\title{
EFEITOS DE EXTRATOS DE PLANTAS NA BIOLOGIA DE Spodoptera frugiperda (J. E. SMITH, 1797) (Lepidoptera: Noctuidae) MANTIDA EM DIETA ARTIFICIAL
}

\author{
Effects of plant extracts on the biology of Spodoptera frugiperda (J. E. Smith, 1797) \\ (Lepidoptera: Noctuidae) maintained under artificial diet
}

\author{
Gilberto Pedreira Santiago ${ }^{1}$ Luiz Evaldo de Moura Pádua², Paulo Roberto Ramalho Silva², \\ Eulália Maria Sousa Carvalho ${ }^{4}$, Cláudio Belmino Maia ${ }^{5}$
}

\begin{abstract}
RESUMO
Avaliaram-se os efeitos dos extratos aquosos a $10 \%$ de folhas e ramos de arruda (Ruta graveolens L.), folhas e ramos de melãode-são-caetano (Momordica charantia L.), folhas do alecrim-pimenta (Lippia sidoides Cham.) e fruto verde de mamona (Ricinus communis L.), sobre a biologia da lagarta-do-cartucho do milho (Spodoptera frugiperda), mantida em dieta artificial. Os parâmetros avaliados foram duração e viabilidade das fases larval e pupal, peso de pupa, fecundidade, fertilidade e longevidade de adultos. Larvas de $S$. frugiperda recém-eclodidas foram colocadas em tubos de ensaio com dieta artificial, contendo os extratos de cada material testado. O extrato aquoso do fruto verde de $R$. communis apresentou bioatividade, nos parâmetros duração larval e pupal e peso de pupa. O extrato aquoso de $R$. graveolens reduziu o peso de pupa. A dieta contendo extrato de folhas e ramos de $M$. charantia reduziu a viabilidade larval e o peso de pupa. O extrato aquoso de folhas de $L$. sidoides não afetou as fases larval e pupal, reduziu a postura e a viabilidade de ovos e aumentou a longevidade de adultos de $S$. frugiperda. A viabilidade de pupa não foi afetada pelos extratos testados.
\end{abstract}

Termos para indexação: Plantas inseticidas, lagarta-do-cartucho, extratos vegetais, controle de insetos.

\section{ABSTRACT}

The effects of aqueous extracts, at 10\% concentration of leaves and branches of Ruta graveolens L., leaves and branches of Momordica charantia L., leaves of Lippia sidoides Cham. and green fruits of Ricinus communis L. were evaluated on the biology of fall armyworm (Spodoptera frugiperda) maintained under artificial diet. The evaluated parameters were: duration and viability of the larval and pupal phases, pupa weight, fecundity, fertility and longevity of adults. Just-hatched larvae of S. frugiperda was placed in test tube with artificial diet containing extracts of each tested material. The aqueous extract of the green fruits of $R$. communis presented bioactivity upon duration and weight of larval and pupal phases. The aqueous extract of $R$. graveolens reduced weight of pupa. The diet containing extract of $M$. charantia reduced larval viability and weight of pupa. The aqueous extract of $L$. sidoides did not affect larval and pupal phases, but reduced the posture and the viability of eggs and increased longevity of adults of S. frugiperda. The viability of pupa was not affected by the extracts.

Index terms: Insecticide plants, fall armyworm, plants extracts, insect control.

(Recebido em 24 de julho de 2006 e aprovado em 17 de maio de 2007)

\section{INTRODUÇÃO}

A lagarta-do-cartucho (Spodoptera frugiperda J. E. Smith,1797) destaca-se como importante praga da cultura do milho causando redução em mais de $25 \%$ da produtividade (WAQUIL \& VILELLA, 2003). Seu controle tem sido feito com o uso de inseticidas químicos. Esses produtos acarretam diversos problemas, tais como resíduos nos alimentos, destruição de inimigos naturais, intoxicação de aplicadores e aparecimento de populações de pragas resistentes aos inseticidas (ROEL et al., 2000).

De acordo com Shin-Foon \& Yu-Tong (1993), produtos naturais extraídos de plantas são fontes de substâncias que podem ser utilizadas no controle de pragas, sendo compatíveis com programas de manejo integrado de pragas (MIP) como uma opção de controle capaz de minimizar os efeitos negativos do uso indiscriminado de inseticidas.

\footnotetext{
'Engenheiro Agrônomo, Mestre em Agronomia - Instituto de Assistência Técnica e Extensão Rural do Piauí/EMATER - Rua João Cabral, s/n - Pirajá 64002-150 - Teresina, PI - gilberto.sant@hotmail.com

'Engenheiro Agrônomo, Doutor em Entomologia, Professor - Departamento de Fitotecnia - Centro de Ciências Agrárias/CCA - Universidade Federal do Piauí/UFPI - Laboratório de Fitossanidade - Campus da Socopo, s/n - 64049-550 - Teresina, PI - lempadua@uol.com.br

${ }^{3}$ Engenheiro Agrônomo, Doutor em Entomologia, Professor - Departamento de Fitotecnia - Centro de Ciências Agrárias/CCA - Universidade Federal do Piauí/UFPI - Laboratório de Fitossanidade - Campus da Socopo, s/n - 64049-550 - Teresina, PI - pramalhoufpi@yahoo.com.br

${ }^{4}$ Engenheira Agrônoma, Mestre em Microbiologia, Professora - Departamento de Fitotecnia - Centro de Ciências Agrárias/CCA - Universidade Federal do Piaui/UFPI - Laboratório de Fitossanidade - Campus da Socopo, s/n - 64049-550 - Teresina, PI - eulaliac@yahoo.com.br

${ }^{5}$ Engenheiro Agrônomo, Doutorando em Fitopatologia - Departamento de Biologia e Química - Centro Superior de Imperatriz/CESI - Universidade Estadual do Maranhão/UEMA - Rua Godofredo Viana, 1300 - Centro - 65901-480 - Imperatriz, MA - claudiobelmino@yahoo.com.br
} 
A família das meliácias vem se destacando como plantas-inseticidas. Roel et al. (2000), avaliando o efeito de diferentes concentrações do extrato acetato de etila de folhas e ramos de Trichilia pallida Swart sobre a lagartado-cartucho, verificaram que o extrato causou mortalidade larval de $100 \%$, em concentração igual ou superior a $0,05 \%$. Góes et al. (2003), testando diferentes extratos vegetais no controle de $S$. frugiperda constataram que houve diferença entre as médias de mortalidade, e o extrato de nim (Azadirachta indica A. Juss.) mais eficiente no controle desse inseto-praga. Plantas tratadas com produtos derivados do A. indica, segundo Schmutterer (1990) inibem a oviposição de diversos lepidópteros, entre os quais $S$. frugiperda.

Vendramim \& Scampini (1997) encontraram 50\% de viabilidade larval de $S$. frugiperda com extrato aquoso do fruto de Melia azedarach L. Resultados semelhantes foram encontrados por Rodriguez \& Vendramim (1996), trabalhando com extrato a $5 \%$ de folhas e ramos de $M$. azedarach incorporados na dieta artificial na biologia de S. frugiperda.

Considerando a importância da lagarta-docartucho, que causa perda significativa na cultura do milho, objetivou-se avaliar o efeito de extratos aquosos de arruda (Ruta graveolens L.), melão-de-são-caetano (Mormodica charantia L.), alecrim-pimenta (Lippia sidoides Cham.) e mamona (Ricinus communis L.), na biologia de $S$. frugiperda, mantida em dieta artificial.

\section{MATERIAL E MÉTODOS}

A pesquisa foi desenvolvida no Laboratório de Fitossanidade do Centro de Ciências Agrárias (CCA) da Universidade Federal do Piauí, à temperatura de $27,0 \pm 2,0^{\circ} \mathrm{C}$, umidade relativa (UR) $60 \% \pm 10,0 \%$ e fotofase de 12 horas.

Para o estabelecimento da colônia inicial de $S$. frugiperda, lagartas foram coletadas em área de cultivo com milho e colocadas em tubos de ensaio de $15 \mathrm{~cm}$ de altura por $1,5 \mathrm{~cm}$ de diâmetro, contendo dieta natural (folhas de milho). Após transformarem-se em pupas e sexadas de acordo com Butt \& Cantu (1962), as mariposas emergentes foram acondicionadas em tubos de PVC de $10 \mathrm{~cm}$ de diâmetro por $20 \mathrm{~cm}$ de altura com as extremidades tampadas com placas de Petri, revestidos internamente com papel de filtro. Diariamente, as mariposas foram alimentadas com mel a $10 \%$, acondicionado em frasco com fio de algodão que permitisse a obtenção do alimento por capilaridade. As posturas foram transferidas para placas de Petri esterilizadas e larvas recém-eclodidas colocadas em tubos de ensaio, contendo a dieta artificial de Bowling (1967), com ou sem extratos para avaliação do efeito das plantas sobre a biologia de $S$. frugiperda.

Para o preparo do extrato aquoso empregaram-se folhas (Lippia sidoides), folhas e ramos (Ruta graveolens, Mormodica charantia) e frutos verdes (Ricinus communis) secos, em estufa a $45^{\circ} \mathrm{C}$ e triturados em moinho de peneira de 17 mesh. Em seguida, foram preparadas suspensões contendo $20 \mathrm{~g}$ de cada espécie vegetal moída e $180 \mathrm{~mL}$ de água destilada. Agitou-se por 5 minutos mantendo-se a suspensão em refrigerador por 48 horas a $5^{\circ} \mathrm{C}$, com o propósito de extrair os compostos hidrossolúveis. Decorrido esse tempo, filtrou-se em tecido tipo 'voile', obtendo-se assim extratos na concentração a $10 \%$.

Para estudar os efeitos das plantas na biologia da Spodoptera frugiperda empregou-se a dieta proposta por Bowling (1967): inicialmente 100 gramas de feijão foi cozido e triturado com $275 \mathrm{~mL}$ de água destilada; adicionou-se a levedura de cerveja ( $15 \mathrm{~g}$ ), ácido ascórbico (3g), nipagin $(1 \mathrm{~g})$ e benzoato de sódio $(0,5 \mathrm{~g})$, dissolvidos em $100 \mathrm{ml}$ de água destilada; posteriormente $1,0 \mathrm{ml}$ de formaldeído e ágar $(9 \mathrm{~g})$ previamente dissolvido em $250 \mathrm{ml}$ de água, sob aquecimento. Após a adição dos ingredientes agitou-se e distribuiu-se em tubos de ensaio esterilizados, na quantidade de 1/3 da capacidade de acordo com os seguintes tratamentos: tratamento 1 (dieta artificial sem extrato), tratamentos 2, 3, 4 e 5 dieta artificial com 5\% do extrato aquoso a $10 \%$ de folhas de alecrim-pimenta, folhas e ramos de arruda e melão-de-são-caetano e fruto verde de mamona, respectivamente .

O delineamento experimental utilizado foi inteiramente casualizado, com 5 (cinco) tratamentos e 5 (cinco) repetições, sendo cada repetição composta por 10 (dez) larvas.

Para avaliação da biologia de $S$. frugiperda dez larvas recém-eclodidas foram inoculadas por tubos e o desenvolvimento observado diariamente. As pupas foram pesadas com 24 horas e após o surgimento das mariposas, casais foram acondicionados em tubos de PVC revestidos internamente com papel de filtro para oviposição, sendo realizada diariamente a contagem dos ovos com auxílio de uma lupa. Três casais do inseto adulto, com a mesma idade de cada tratamento, foram colocados em gaiola, para avaliação da longevidade, fecundidade e fertilidade dos adultos.

Os parâmetros avaliados foram: duração, viabilidade larval e pupal, peso de pupa, fecundidade, fertilidade e longevidade dos adultos.

Os resultados foram submetidos à análise de variância e as médias comparadas pelo teste Tukey, a nível de $5 \%$ de probabilidade. 


\section{RESULTADOS E DISCUSSÃO}

$\mathrm{Na}$ fase larval, o tratamento contendo extrato aquoso de frutos verdes de $R$. communis diferiu significativamente da testemunha nos parâmetros duração e viabilidade larval, demonstrando efeitos bioativos nessa fase da biologia do inseto (Tabela 1). Nesse tratamento ocorreu um alongamento da duração da fase larval, inibição do crescimento e deterrência alimentar. Com $R$. graveolens, $M$. charantia e $L$. sidoides as durações das fases larvais não diferiram da testemunha sem extratos vegetais. A viabilidade larval também foi reduzida significativamente quando empregaram-se os extratos de $R$. communis e $M$. charantia. Quanto aos demais tratamentos não houve diferença significativa em relação à testemunha.

Avaliando o efeito do extrato aquoso de Melia azedarach, Vendramim \& Scampini (1997) verificaram que lagartas de Spodoptera frugiperda alimentadas com folhas de milho tratadas com esse extrato apresentaram menor peso, desenvolvimento mais lento e menor viabilidade.

Torrecillas \& Vendramim (2001) relataram forte atividade inseticida de extrato aquoso de Trichilia pallida Swartz (Meliaceae) a 1\%, matando todas as lagartas de $S$. frugiperda antes que atingissem 10 dias de idade, enquanto que o extrato a $0,1 \%$ reduziu a sobrevivência e o peso larval e prolongou o período de desenvolvimento do inseto.

Mazzonetto \& Vendramim (2003), avaliando material seco pulverizado de origem vegetal sobre Acanthoscelides obtectus (Say) (Coleoptera: Bruchidae) em feijão armazenado, verificaram que $R$. graveolens provocou repelência.

Medeiros \& Boiça Júnior (2005), testando extratos de amêndoas de Azadirachta indica e frutos de Sapindus saponaria L. (sabão-de-soldado), aplicados em disco de folhas de couve constataram efeitos na alimentação de lagartas de Ascia monuste orseis (Latreille) (Lepidoptera: Pieridae), possivelmente com propriedades deterrentes e/ ou supressoras de alimentação.

De acordo com Martinez \& Emden (2001) a inibição de crescimento é função da reduzida ingestão de alimentos, pouca habilidade da conversão de nutrientes em crescimento, enquanto o alongamento da duração da fase larval se verifica em geral pela reduzida ingestão de alimentos em razão da existência de um inibidor ou vários inibidores no alimento, ou uma inadequação nutricional do substrato alimentar.

O extrato aquoso de $R$. communis a $10 \%$ promoveu aumento na duração da fase pupal diferindo significativamente da testemunha. (Tabela 2). Em relação à viabilidade pupal verificou-se que os extratos aquosos avaliados não diferiram estatisticamente entre si, indicando não terem influência sobre $S$. frugiperda. Os extratos aquosos de $R$. graveolens, $M$. charantia e $R$. communis a $10 \%$ diminuíram o peso médio de pupa. Quanto ao extrato de L. sidoides nenhum dos parâmetros estudados apresentaram alterações na fase pupal.

Resultados semelhantes foram encontrados por Roel et al. (2000) que constataram que apenas o extrato de acetato de etila de Trichilia pallida Swartz, na concentração de $0,006 \%$ afetou a fase pupal, alongando a duração e reduzindo o peso sem afetar a viabilidade de $S$. frugiperda. Bogorni \& Vendramim (2005) também não constataram efeitos de extratos de folhas e ramos de Trichilia catigua, sobre a fase de pupa dessa praga.

Nos tratamentos com $R$. graveolenses, $M$. charantia e $R$. communis foram constatadas também deformações de pupa de $4 \%, 24,33 \%$, e 3,33\% respectivamente. Observações semelhantes foram constatadas por Thomazini et al. (2000) com

Tabela 1 - Duração e viabilidade da fase de larva de Spodoptera frugiperda mantida na dieta de Bowling (1967), contendo extratos aquosos de espécies vegetais a $10 \%$. T $\left({ }^{\circ} \mathrm{C}\right)=27 \pm 2$; UR $(\%)=60 \pm 10$; fotofase $=12$ horas. Teresina (PI), 2005.

\begin{tabular}{|c|c|c|c|c|c|c|c|}
\hline \multirow[b]{2}{*}{ Tratamentos } & \multirow[b]{2}{*}{ Estrutura Vegetal } & \multicolumn{3}{|c|}{ Duração (dias) } & \multicolumn{3}{|c|}{ Viabilidade (\%) } \\
\hline & & 墨 & 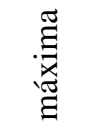 & 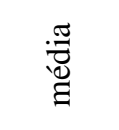 & : & 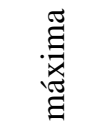 & 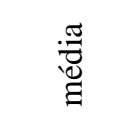 \\
\hline Testemunha & - & 22,4 & 25,0 & $24,0 \mathrm{~B}$ & 70,0 & 80,0 & $74,0 \mathrm{~A}$ \\
\hline Ruta graveolens & Folhas e ramos & 26,0 & 28,7 & $27,3 \mathrm{~B}$ & 30,0 & 80,0 & $56,0 \mathrm{AB}$ \\
\hline Momordica charantia & Frutos e ramos & 22,6 & 27,5 & $25,6 \mathrm{~B}$ & 10,0 & 50,0 & $30,0 \mathrm{~B}$ \\
\hline Lippia sidoides & Folhas & 24,8 & 29,8 & $27,5 \mathrm{~B}$ & 30,0 & 70,0 & $52,0 \mathrm{AB}$ \\
\hline Ricinus communis & Fruto verde & 32,0 & 40,5 & $35,8 \mathrm{~A}$ & 20,0 & 50,0 & $34,0 \mathrm{~B}$ \\
\hline $\mathrm{CV}(\%)$ & & & 7,968 & & & 30,284 & \\
\hline
\end{tabular}

Médias seguidas de mesma letra na coluna, não diferem entre si pelo teste Tukey, a 5\% de probabilidade. 
extratos aquosos de Trichilia pallida, na traça do tomateiro e Martinez \& Emden (2001) em Spodoptera littoralis.

Analisando os dados da Tabela 3 pode-se observar que o extrato de $M$. charantia exerceu forte efeito sobre a fase adulta do inseto inibindo totalmente a postura e aumentando a longevidade. Os demais extratos proporcionaram menores efeitos reduzindo o número de ovos, quando comparados à testemunha. $\mathrm{O}$ extrato de $R$. graveolens além de diminuir a postura também reduziu a longevidade dos adultos. Tais constatações indicam que o emprego desses extratos podem reduzir a fecundidade e fertilidade do inseto.

A ação deterrente de extratos vegetais na oviposição de insetos também foi constatada por outros autores. Medeiros et al. (2005), avaliando o efeito de diferentes extratos na oviposição da traça-das-crucíferas, em couve verificaram que os extratos de Enterolobium contortisilliquum, Sapindus saponaria (frutos) e Trichilia pallida (folhas) foram os mais eficientes, apresentando $100 \%$ de deterrência. Souza \& Vendramim (2001) testaram a atividade inseticida de extratos aquosos de meliáceas sobre ovos e ninfas de Bemisia tabaci biótipo B, em tomateiro e constataram efeito ovicida de extratos de frutos verdes e de folhas de Melia azedarach.

Empregando extrato aquoso de $R$. communis, não foi possível obter dados da longevidade média e viabilidade dos ovos em virtude de não se conseguir acasalar machos e fêmeas da mesma idade de $S$. frugiperda, em função da baixa viabilidade larval.

Tabela 2 - Duração, viabilidade e peso de pupa de Spodoptera frugiperda mantida na dieta de Bowling (1967) contendo extratos aquosos de espécies vegetais a $10 \%$. T $\left({ }^{\circ} \mathrm{C}\right)=27 \pm 2$; UR $(\%)=60 \pm 10$; fotofase $=12$ horas. Teresina $(\mathrm{PI}), 2005$.

\begin{tabular}{|c|c|c|c|c|c|c|c|c|c|}
\hline \multirow[b]{2}{*}{ Tratamentos } & \multicolumn{3}{|c|}{ Duração (dias) } & \multicolumn{3}{|c|}{ Viabilidade (\%) } & \multicolumn{3}{|c|}{ Peso de pupa (mg) } \\
\hline & 自 & $\begin{array}{l}\underset{\Xi}{\Xi} \\
\stackrel{\Xi}{\Xi} \\
\stackrel{\Xi}{\Xi}\end{array}$ & : & 墨 & 祩 & $\frac{\pi}{\stackrel{\Xi}{\Xi}}$ & 祃 & 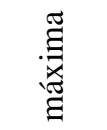 & $\stackrel{\stackrel{\Xi}{\Xi}}{\stackrel{\Xi}{\Xi}}$ \\
\hline Testemunha & 7.7 & 8,4 & $7,4 \mathrm{~B}$ & 71,4 & 100 & $89,2 \mathrm{~A}$ & 195,1 & 224,2 & $208,9 \mathrm{~A}$ \\
\hline Ruta graveolens & 8,1 & 11,0 & $9,1 \mathrm{AB}$ & 66,6 & 87,5 & $76,3 \mathrm{~A}$ & 164,3 & 185,8 & 170,4B \\
\hline Momordica charantia & 8,0 & 9,0 & $8,4 \mathrm{~B}$ & 20,0 & 100 & $62,3 \mathrm{~A}$ & 160,0 & 198,2 & $180,4 \mathrm{~B}$ \\
\hline Lippia sidoides & 7,0 & 9,0 & $8,2 \mathrm{~B}$ & 33,3 & 100 & $60,9 \mathrm{~A}$ & 189,6 & 222,5 & $208,9 \mathrm{~A}$ \\
\hline Ricinus communis & 9,2 & 13,0 & $10,4 \mathrm{~A}$ & 20,0 & 100 & $59,9 \mathrm{~A}$ & 145,3 & 177,5 & $163,7 \mathrm{~B}$ \\
\hline $\mathrm{CV}(\%)$ & \multicolumn{3}{|c|}{11,418} & \multicolumn{3}{|c|}{35,175} & \multicolumn{3}{|c|}{6,70} \\
\hline
\end{tabular}

Médias seguidas de mesma letra, não diferem entre si pelo teste Tukey, a 5\% de probabilidade.

Tabela 3 - Postura, viabilidade dos ovos e longevidade de machos e fêmeas de Spodoptera frugiperda, mantida na dieta de Bowling (1967), contendo extratos aquosos de espécies vegetais a 10\%. T( $\left.{ }^{\circ} \mathrm{C}\right)=27 \pm 2 ; \mathrm{UR}(\%)=60 \pm 10$; fotofase $=12$ horas. Teresina $(\mathrm{PI}), 2005$.

\begin{tabular}{|c|c|c|c|c|c|c|c|c|c|}
\hline \multirow[b]{2}{*}{ Tratamentos } & \multicolumn{3}{|c|}{ Postura ( $n^{\circ}$ de ovos) } & \multicolumn{3}{|c|}{ Viabilidade dos ovos (\%) } & \multicolumn{3}{|c|}{ Longevidade (dias) } \\
\hline & $\stackrel{\Xi}{\Xi}$ & 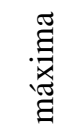 & $\frac{\mathbb{\Xi}}{\stackrel{\Xi}{\Xi}}$ & 节 & 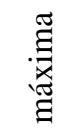 & : & $\begin{array}{l}\stackrel{̊}{0} \\
\stackrel{\Xi}{\Xi}\end{array}$ & 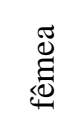 & $\frac{\mathbb{\Xi}}{\stackrel{\Xi}{\Xi}}$ \\
\hline Testemunha & 31 & 501 & 230 & 0 & 501 & 90 & 9,5 & 15,5 & 12,5 \\
\hline Ruta graveolens & 55 & 312 & 200 & 0 & 100 & 25 & 10 & 11 & 10,5 \\
\hline Momordica charantia & 0 & 0 & 0 & - & - & - & 10,5 & 19 & 14,7 \\
\hline Lippia sidoides & 25 & 414 & 178 & 0 & 100 & 62 & 15 & 16 & 15,5 \\
\hline Ricinus communis $^{1}$ & - & - & - & - & - & - & - & - & - \\
\hline
\end{tabular}

${ }^{1}$ Os dados de postura, viabilidade e longevidade dos ovos não foi possível contabilizar por não se conseguir acasalar macho e fêmea de mesma idade. 


\section{CONCLUSÕES}

O extrato do fruto verde de R. communis L. a $10 \%$ apresentou bioatividade, na duração e peso das fases larval e pupal de $S$. frugiperda.

O extrato das folhas e ramos de $R$. graveolens L. a $10 \%$ reduziu o peso de pupa de $S$. frugiperda

O extrato das folhas e ramos de M. charantia L. a $10 \%$ reduziu a viabilidade larval e peso de pupa de $S$. frugiperda

O extrato de folhas de $L$. sidoides L. a $10 \%$ não afetou as fases larval e pupal, mas reduziu a postura e a viabilidade, e aumentou a longevidade de adultos de $S$. frugiperda.

Os extratos testados não proporcionaram efeitos na viabilidade de pupas de $S$. frugiperda.

\section{REFERÊNCIAS BIBLIOGRÁFICAS}

BOGORNI, P. C.; VENDRAMIM, J. D. Efeito subletal de extratos aquosos de Trichilia spp. sobre o desenvolvimento de Spodoptera frugiperda (J. E. Smith) (Lepidoptera: Noctuidae) em milho. Neotropical Entomology, Londrina, v. 34, n. 2, p. 311-317, mar./abr. 2005.

BOWLING, C. C. Rearing of two lepidopterous pests of rice on common artificial diet. Annals of the Entomological Society of America, College Park, v. 60, n. 6, p. 1215-1216, 1967.

BUTT, B. A.; CANTU, E. Sex determination of lepidopterous pupae. Washington, DC: USDA, 1962. 7 p.

GÓES, G. B.; NERI, D. K. P.; CHAVES, J. W. N.; MARACAJÁ, P. B. Efeito de extratos vegetais no controle de Spodoptera frugiperda (J.E. Smith) (LEPIDOPTERA: NOCTUIDAE). Caatinga, Mossoró, v. 16, n. 1/2, p. 47-49, dez. 2003.

MARTINEZ, S. S.; EMDEN, H. F. van. Redução do crescimento, deformidades e mortalidade Spodoptera littoralis (Boisduval) (Lepidoptera: Noctuidae) causadas por Azadiractina. Neotropical Entomology, Piracicaba, v. 30, n. 1, p. 113-125, Mar. 2001.

MAZZONETTO, F.; VENDRAMIM, J. D. Efeito de pós de origem vegetal sobre Acanthoscelides obtectus (Say) (Coleoptera: Bruchidae) em feijão armazenado. Neotropical Entomology, Piracicaba, v. 32, n. 1, p. 145-149, jan./mar. 2003.

MEDEIROS, C. A. M.; BOIÇA JUNIOR, A. L. Efeitos da aplicação de extratos aquosos em couve na alimentação de lagarta de Ascia monuste orseis. Bragantia, Campinas, v. 64, n. 4, p. 633-641, 2005.
MEDEIROS, C. A. M.; BOIÇA JUNIOR, A. L.; TORRES, A. L. Efeitos de extratos aquosos de plantas na oviposição da traça-das-crucíferas, em couve. Bragantia, Campinas, v. 64 , n. 2, maio/ago. 2005.

RODRIGUEZ, H. C.; VENDRAMIM, J. D. Toxicidad de extractos acuosos de Meliaceae en Spodoptera frugiperda (Lepidoptera : Noctuidae). Manejo Integrado de Plagas, Turrialba, San Jose, n. 42, p. 14-22, 1996.

ROEL, A. R.; VENDRAMIM, J. D.; FRIGHETTO, R. T. S.; FRIGHETTO, N. Efeito do extrato acetato de etila de Trichilia pallida Swartz (Meliaceae) no desenvolvimento e sobrevivência da lagarta-do-cartucho. Bragantia, Campinas, v. 59, n. 1, p. 53-58, 2000.

SCHMUTTERER, H. Properties and potential of natural pesticides from the neem tree, Azadirachta indica. Annual Review Entomology, Palo Alto, v. 35, p. 271-297, 1990.

SHIN-FOON, C.; YU-TONG, Q. Experiments on the application of botanical insecticides for the control of diamondback moth in South China. Journal Applied Entomology, Hamburg, v. 116, p. 479-486, 1993.

SOUZA, A. P.; VENDRAMIM, J. D. Atividade inseticida de extratos aquosos de meliáceas sobre a mosca-branca Bemisia tabaci (Genn.) biótipo B (Hemiptera: Aleyrodidae). Neotropical Entomology, Piracicaba, v. 30, n. 1, p. 133-137, 2001 .

THOMAZINI, A. P. B. W.; VENDRAMIM, J. D.; LOPES, M. T. R. Extratos aquosos de Trichillia pallida e a traçado-tomateiro. Scientia Agrícola, Piracicaba, v. 57, n. 1, p. 13-17, 2000.

TORRECILLAS, S. M.; VENDRAMIM, J. D. Extratos aquosos de ramos de Trichilia pallida e o desenvolvimento de Spodoptera frugiperda em genótipos de milho. Scientia Agricola, Piracicaba, v. 58, n. 1, p. 27-31, jan./mar. 2001.

VENDRAMIM, J. D.; SCAMPINI, P. J. Efeito do extrato aquoso de Melia azedarach sobre o desenvolvimento de Spodoptera frugiperda (J. E. Smith) em dois genótipos de milho. Revista de Agricultura, Piracicaba, v. 72, n. 2, p. 158-170, 1997.

WAQUIL, J. M.; VILELLA, F. M. F. Gene bom. Revista Cultivar, São Paulo, v. 49, p. 22-26, 2003. 